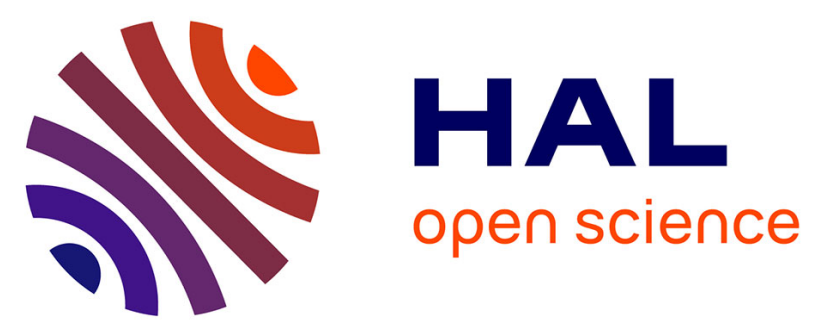

\title{
HYTHEC: An EC funded search for a long term massive hydrogen production route using solar and nuclear technologies
}

\author{
Alain Le Duigou, Jean-Marc Borgard, Bruno Larousse, Denis Doizi, Ray \\ Allen, Bruce Ewan, Geoff H Priestman, Rachael Elder, Robin Devonshire, \\ Victor Ramos, et al.
}

\section{To cite this version:}

Alain Le Duigou, Jean-Marc Borgard, Bruno Larousse, Denis Doizi, Ray Allen, et al.. HYTHEC: An EC funded search for a long term massive hydrogen production route using solar and nuclear technologies. International Journal of Hydrogen Energy, 2007, 32 (10-11), pp.1516-1529. 10.1016/j.ijhydene.2006.10.047 . cea-02512145

HAL Id: cea-02512145

https://hal-cea.archives-ouvertes.fr/cea-02512145

Submitted on 19 Mar 2020

HAL is a multi-disciplinary open access archive for the deposit and dissemination of scientific research documents, whether they are published or not. The documents may come from teaching and research institutions in France or abroad, or from public or private research centers.
L'archive ouverte pluridisciplinaire HAL, est destinée au dépôt et à la diffusion de documents scientifiques de niveau recherche, publiés ou non, émanant des établissements d'enseignement et de recherche français ou étrangers, des laboratoires publics ou privés. 


\title{
HYTHEC: An EC funded search for a long term massive hydrogen production route using solar and nuclear technologies
}

\author{
Alain Le Duigou ${ }^{\mathrm{a}, *}$, Jean-Marc Borgard ${ }^{\mathrm{a}}$, Bruno Larousse $^{\mathrm{a}}$, Denis Doizi ${ }^{\mathrm{a}}$, Ray Allen ${ }^{\mathrm{b}}$, \\ Bruce C. Ewan ${ }^{b}$, Geoff H. Priestman ${ }^{b}$, Rachael Elder ${ }^{b}$, Robin Devonshire ${ }^{b}$, Victor Ramos ${ }^{b}$, \\ Giovanni Cerri ${ }^{\mathrm{c}}$, Coriolano Salvini ${ }^{\mathrm{c}}$, Ambra Giovannelli ${ }^{\mathrm{c}}$, Giovanni De Maria ${ }^{\mathrm{c}}$, Claudio Corgnale ${ }^{\mathrm{c}}$, \\ Sergio Brutti $^{\mathrm{c}}$, Martin Roeb ${ }^{\mathrm{d}}$, Adam Noglik ${ }^{\mathrm{d}}$, Peter-Michael Rietbrock ${ }^{\mathrm{d}}$, Stefan Mohr ${ }^{\mathrm{d}}$, \\ Lamark de Oliveira $^{\mathrm{d}}$, Nathalie Monnerie ${ }^{\mathrm{d}}$, Mark Schmitz ${ }^{\mathrm{d}}$, Christian Sattler ${ }^{\mathrm{d}}$, \\ Alfredo Orden Martinez ${ }^{\mathrm{e}}$, Daniel de Lorenzo Manzano ${ }^{\mathrm{e}}$, Jorge Cedillo Rojas ${ }^{\mathrm{e}}$, \\ Stéphane Dechelotte $^{\mathrm{f}}$, Olivier Baudouin ${ }^{\mathrm{f}}$ \\ a Department of Physico Chemistry, Commissariat à l'Energie Atomique/Saclay, 91191 Gif-Sur-Yvette Cedex, France \\ ${ }^{\mathrm{b}}$ The University of Sheffield, Firth Court, Western Bank, S102TN Sheffield, UK \\ ${ }^{\mathrm{c}}$ Università degli Studi ROMA TRE, Via della Vasca Navale 79, 00146 Roma, Italy \\ d Deutsches Zentrum für Luft-und Raumfahrt e.V., Linder Höhe, 51147 Köln, Germany

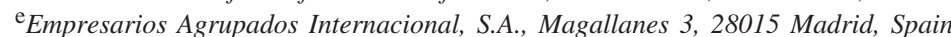 \\ ${ }^{\mathrm{f}}$ ProSim SA, Stratège Bâtiment A, BP 2738, F-31312 Labège, France
}

\begin{abstract}
The objective of HYTHEC-HYdrogen THErmo-chemical Cycles—is to investigate the effective potential for massive hydrogen production of the S-I thermo-chemical cycle, and to compare it with the hybrid S Westinghouse (WH) cycle. The project aims to conduct flow-sheeting, industrial scale-up, safety and costs modelling, to improve the fundamental knowledge and efficiency of the $\mathrm{S}-\mathrm{I}$ cycle $\mathrm{H}_{2}$ production step, and to investigate a solar primary energy source for the $\mathrm{H}_{2} \mathrm{SO}_{4}$ decomposition step which is common to both the cycles. Initial reference flowsheets have been prepared and compared. First data and results are available now on the coupling of S-I cycle with a very high temperature nuclear reactor, scale-up to industrial level and cost estimation, improvement of the knowledge of the $\mathrm{HI}_{x}$ mixture $(\mathrm{S}-\mathrm{I}$ cycle) and membrane separation, splitting of sulphuric acid using a solar furnace, and plant concepts regarding the WH process.
\end{abstract}

Keywords: HYTHEC; Hydrogen production; Thermo-chemical; Sulphur-iodine cycle; Hybrid-sulphur cycle; Heat source; Nuclear energy; Safety; Costs

\section{Introduction}

Today, hydrogen is mainly produced from fossil resources. In the long term, given the prospect of an increasing energy demand $(+20 \%$ by 2020 , expected to double by 2030 , with a possible three-fold increase by 2050), a lack of fossil resources

\footnotetext{
* Corresponding author.

E-mail addresses: alain.le-duigou@cea.fr (A.L. Duigou), r.w.k.allen@shef.ac.uk (R. Allen), cerri@uniroma3.it (G. Cerri), Martin.roeb@dlr.de (M. Roeb), aom@empre.es (A.O. Martinez), olivier.baudouin@prosim.net (O. Baudouin).
}

and limitations on the release of greenhouse gases, only water and biomass are viable, long term candidate raw materials for hydrogen production. The two processes that have the greatest likelihood of successful massive hydrogen production from water are electrolysis and thermo-chemical cycles. The thermochemical cycles are processes where water is decomposed into hydrogen and oxygen via chemical reactions using intermediate elements which are recycled. As the heat can be directly used, these cycles have the potential of a better efficiency than alkaline electrolysis. The required energy can be either provided by nuclear energy or by solar energy, and, since the production requires a continuous supply of heat, hybrid solutions including 
solar and nuclear energy input are conceivable and desirable. Among the whole project theoretical and experimental work presented in this paper, a special description of the development of a dedicated solar receiver-reactor for the decomposition of sulphuric acid, chemical step common to sulphur-iodine and hybrid-sulphur thermo-chemical cycles, is given.

\section{HYTHEC: the search for an efficient hydrogen production route from renewables}

The sulfur-iodine (S-I) cycle (Fig. 1) was extensively studied by the General Atomics Company [1]. Japan has recently built a small pilot plant of this process [2]. Thus, the S-I cycle seems to be the best known, internationally leading candidate, as a promising thermo-chemical option. Beyond that, the hybrid-sulfur (Westinghouse-WH) process (Fig. 2) which offers a combination of electrolysis and thermo-chemical reactions is also the focus of much international attention. The objective of HYTHEC is to investigate, and compare, the effective potential of those two leading candidates, which have in common the high temperature process step: the $\mathrm{H}_{2} \mathrm{SO}_{4}$ decomposition reaction. These thermo-chemical options can only be considered viable if they meet two major criteria: demonstrated large scale technical feasibility, and competitive cost.

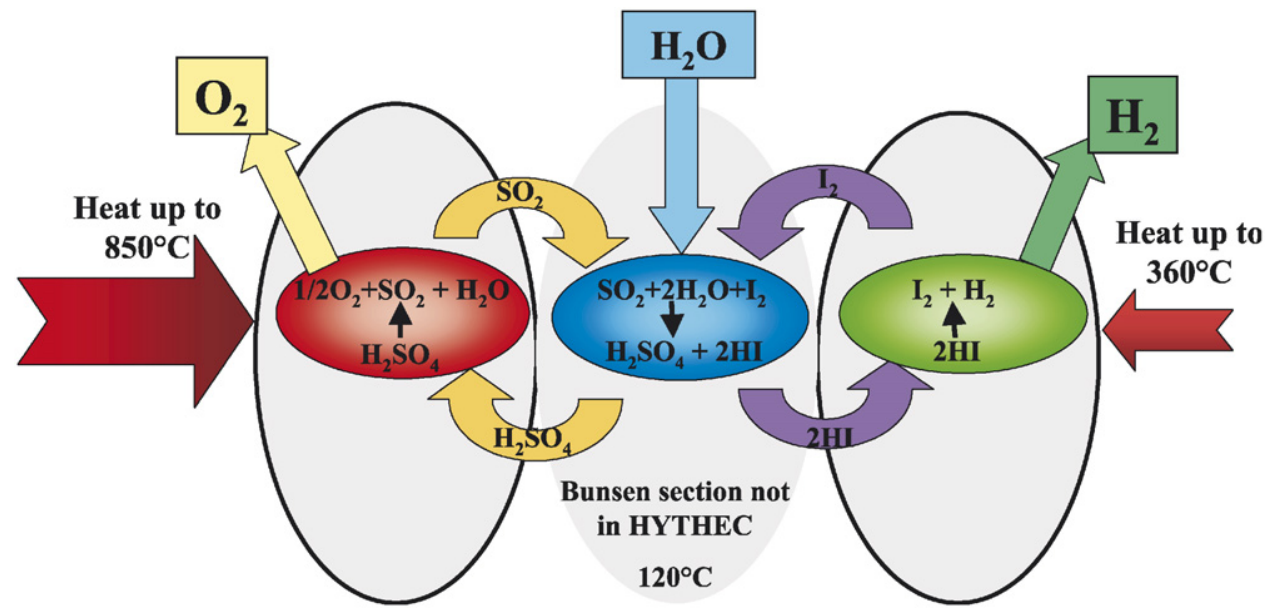

Fig. 1. The sulphur-iodine (S-I) cycle.

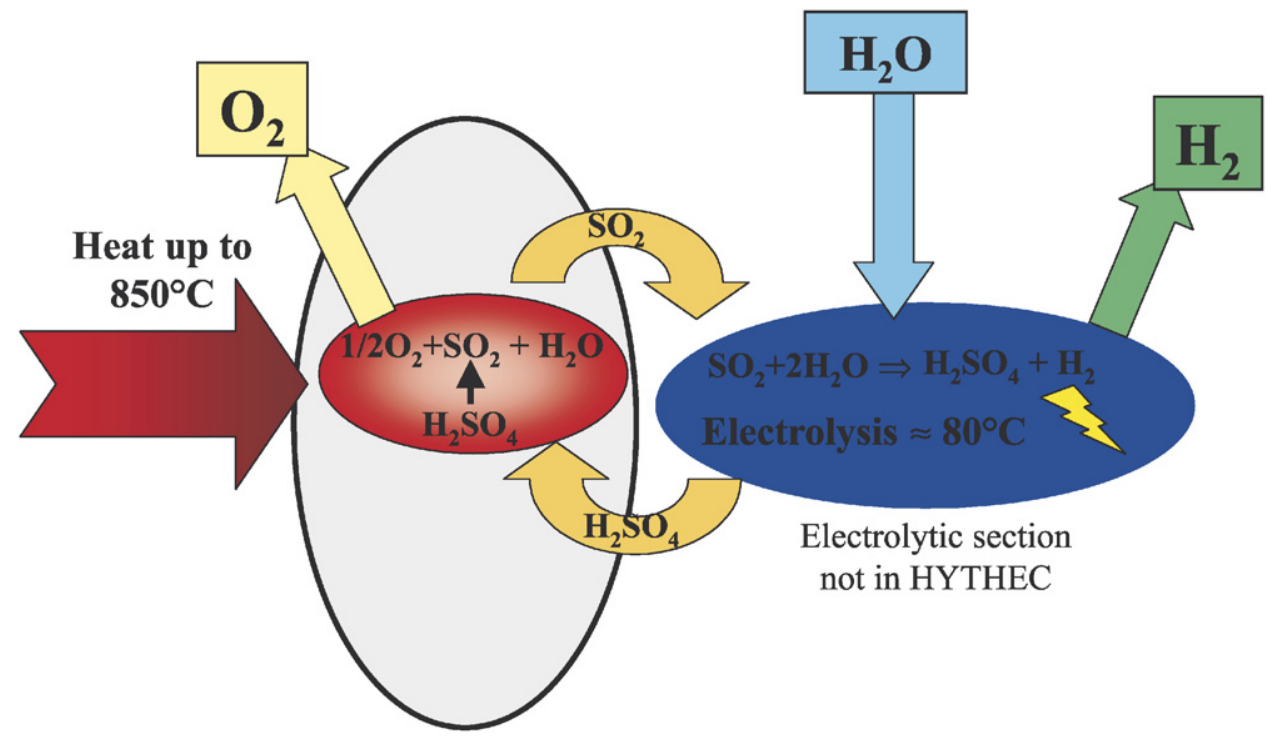

Fig. 2. The hybrid-sulfur (WH) cycle. 


\section{Basic knowledge and needs for S-I and WH thermo-chemical cycles}

\subsection{The $S-I$ cycle}

In terms of the chemical reaction stages involved, the S-I process may be summarised as follows:

$$
\begin{array}{ll}
\mathrm{R} 1 & 9 \mathrm{I}_{2}+\mathrm{SO}_{2}+16 \mathrm{H}_{2} \mathrm{O} \rightarrow\left(2 \mathrm{HI}+10 \mathrm{H}_{2} \mathrm{O}+8 \mathrm{I}_{2}\right)+\left(\mathrm{H}_{2} \mathrm{SO}_{4}+\right. \\
& \left.4 \mathrm{H}_{2} \mathrm{O}\right)\left(120^{\circ} \mathrm{C}\right), \\
\text { R2 } & 2 \mathrm{HI} \rightarrow \mathrm{H}_{2}+\mathrm{I}_{2}\left(220-330^{\circ} \mathrm{C}\right), \\
\mathrm{R} 3 & \mathrm{H}_{2} \mathrm{SO}_{4} \rightarrow \mathrm{SO}_{2}+\mathrm{H}_{2} \mathrm{O}+\frac{1}{2} \mathrm{O}_{2}\left(850^{\circ} \mathrm{C}\right) .
\end{array}
$$

These sum to

$$
\mathrm{R} 4 \mathrm{H}_{2} \mathrm{O} \rightarrow \mathrm{H}_{2}+\frac{1}{2} \mathrm{O}_{2} \text {. }
$$

The first reaction, called the Bunsen-reaction, proceeds exothermically in the liquid phase and produces two immiscible aqueous acid phases whose compositions are aqueous sulphuric acid and a mixture of hydrogen iodide, iodine and water named $\mathrm{HI}_{x}$. These acids are concentrated and the excesses of water and iodine are recycled in $\mathrm{R} 1$. $\mathrm{HI}$ and $\mathrm{H}_{2} \mathrm{SO}_{4}$ are then decomposed according to reactions $\mathrm{R} 2$ and $\mathrm{R} 3$. Reaction $\mathrm{R} 2$ is the HI decomposition step with little endothermic heat of reaction. Reaction R3 is the major endothermic reaction releasing water, oxygen and sulfur dioxide. It takes place in the vapour phase in a catalytic reactor at about $900^{\circ} \mathrm{C}$. The concentration by distillation of the two acids $\mathrm{HI}$ and $\mathrm{H}_{2} \mathrm{SO}_{4}$ involves significant energy consumption, which has a direct influence on the efficiency of the cycle. One of the major challenges of this cycle is to reduce these excesses of water and iodine or to find separation processes that consume less energy than distillation. Among all options available for the $\mathrm{HI}_{x}$ section (extractive distillation using phosphoric acid, electrodialysis and so on), HYTHEC is focusing on the reactive distillation concept as proposed by Knoche et al. [3]. Their approach allows this step to be done in one reactor so it seems to have the highest efficiency potential. An improved version has already been proposed in [4]. However, necessary vapour-liquid equilibrium data and energy integration calculations are not available so that it is difficult to develop a reliable conceptual design. On the other hand, we propose to investigate the use of membranes in the distillation section of $\mathrm{HI}_{x}$ in order to get the maximum $\mathrm{HI}$ concentration in the vapour phase, and therefore to improve the overall thermal efficiency of the process: a complete literature review must be performed, and test rigs will be built to investigate membrane distillation.

The present flow-sheets exhibit a reaction $\mathrm{R} 3$ split into the following steps, the $\mathrm{SO}_{3}$ decomposition taking place at about $850^{\circ} \mathrm{C}$. The efficiency is sensitive to the temperature of this latter reaction, and only high temperature heat sources, such as nuclear VHTR or solar energy devices, may be relevant for this process step:

$\mathrm{L}_{1}=\left(\mathrm{H}_{2} \mathrm{SO}_{4}+4 \mathrm{H}_{2} \mathrm{O}\right)_{1} \Rightarrow\left(\mathrm{H}_{2} \mathrm{SO}_{4}\right)_{1}+\left(4 \mathrm{H}_{2} \mathrm{O}\right)_{\mathrm{g}} \quad\left(300^{\circ} \mathrm{C}\right)$,

$\left(\mathrm{H}_{2} \mathrm{SO}_{4}\right)_{1} \Rightarrow\left(\mathrm{H}_{2} \mathrm{SO}_{4}\right)_{\mathrm{g}} \quad\left(360^{\circ} \mathrm{C}\right)$,

$$
\begin{aligned}
& \left(\mathrm{H}_{2} \mathrm{SO}_{4}\right)_{\mathrm{g}} \Rightarrow\left(\mathrm{SO}_{3}\right)_{\mathrm{g}}+\left(\mathrm{H}_{2} \mathrm{O}\right)_{\mathrm{g}} \quad\left(400^{\circ} \mathrm{C}\right), \\
& \left(\mathrm{SO}_{3}\right)_{\mathrm{g}} \Rightarrow\left(\mathrm{SO}_{2}\right)_{\mathrm{g}}+\frac{1}{2} \mathrm{O}_{2} \quad\left(870{ }^{\circ} \mathrm{C}\right) .
\end{aligned}
$$

A solar furnace gives the opportunity to study the chemical reaction in an original manner, both at nuclear VHTR reactor temperatures (HTR: $850-900^{\circ} \mathrm{C}$ ) and at higher ones $\left(1100-1200^{\circ} \mathrm{C}\right)$. The kinetics could thus be improved, and the possibility exists to directly split a concentrated $\mathrm{H}_{2} \mathrm{SO}_{4}$ mixture into $\mathrm{SO}_{2}+\frac{1}{2} \mathrm{O}_{2}$, even without the use of a catalyst as needed at temperatures of about $850^{\circ} \mathrm{C}$.

\subsection{The hybrid-sulphur (WH) cycle}

This cycle is a two-step thermo-chemical cycle for decomposing water into hydrogen and oxygen. The reaction scheme is as follows:

$$
\begin{aligned}
\text { R9 } & \mathrm{SO}_{2}(\mathrm{~g})+2 \mathrm{H}_{2} \mathrm{O}(\mathrm{l})=\mathrm{H}_{2}(\mathrm{~g})+\mathrm{H}_{2} \mathrm{SO}_{4} \text { (aqueous) } \\
& \left(\text { electrolysis, } 25-100^{\circ} \mathrm{C}\right), \\
\mathrm{R} 10 & \mathrm{H}_{2} \mathrm{SO}_{4}(\mathrm{~g})=\mathrm{H}_{2} \mathrm{O}(\mathrm{l})+\mathrm{SO}_{2}(\mathrm{~g})+\frac{1}{2} \mathrm{O}_{2}(\mathrm{~g}) \\
& \text { (thermo-chemical, } \left.850^{\circ} \mathrm{C}\right) .
\end{aligned}
$$

The cycle has the potential for achieving high thermal efficiencies, while using common and inexpensive chemicals.

Due to the fact that the WH cycle has the decomposition of the sulphuric acid in common with the S-I cycle, it is worthwhile studying this cycle in the same project, even if the study is limited to literature review and engineering calculations to minimise cost.

For both S-I and WH cycles, industrial scale-up studies are of great importance, for the assessments of the safety aspects of the process, the feasibility of the main components at industrial scale, and $\mathrm{H}_{2}$ production costs. Specific R\&D needs may arise. For this purpose, the possible cycle coupling schemes will be modelled, and will also allow for optimisation of the cycle energy balances and efficiencies. Moreover, the cycle safety aspects during normal and transient operation will be studied using this model. The plant concepts will be analysed regarding their comparative economic potential in comparison with the existing processes. Beyond that, the combination of electrolysis and thermo-chemical process steps in the WH process offers the opportunity for a combined use of solar and nuclear heat and this will be considered as well.

The partners involved in the Project are: Commissariat à l'Energie Atomique (CEA-F) (coordination, S-I and WH reference basic flow-sheets, vapour liquid equilibrium experiments), University of Sheffield (USFD-UK) (membrane distillation of $\mathrm{HI}_{x}$ and modelling), Università degli studi, ROMA TRE (DIMI-I) (components sizing and techno-economical evaluations, solar $\mathrm{H}_{2} \mathrm{SO}_{4}$ decomposition flow modelling), Deutsches Zentrum für Luft und Raumfahrt (DLR-D) $\left(\mathrm{H}_{2} \mathrm{SO}_{4}\right.$ decomposition in a solar furnace, $\mathrm{WH}$ coupling to a solar and/or nuclear heat source), Empresarios Agrupados (EA-SP) (coupling to reactor and safety evaluations, thermostructural analysis of the solar test reactor), PROSIM-SA (F) (implementation of the S-I models in the code). 


\section{The HYTHEC project}

4.1. Assessment of the $S-I$ thermo-chemical cycle; technical and industrial viability

A critical analysis of previous flow-sheets published in the literature has been undertaken with optimisation of heat transfer using the ProSim code. The $\mathrm{H}_{2} \mathrm{SO}_{4}$ section is handled with a multiple flash distillation, followed by $\mathrm{H}_{2} \mathrm{SO}_{4}$ evapouration and $\mathrm{SO}_{3}$ decomposition. $\mathrm{SO}_{3}$ is recombined in the late stages of the distillation process to optimise the global efficiency. The $\mathrm{HI}_{x}$ section is handled by a reactive distillation process as proposed in [4]. The flash at the exit of the column is needed to recover some of the latent heat of water for efficiency optimisation. The whole flow-sheet is given in Fig. 3. Realist efficiency of S-I cycle (considering HHV) is $\sim 35 \%$.

The coupling of the $\mathrm{S}-\mathrm{I}$ cycle to a nuclear reactor has been studied. Due to the high temperatures needed for the $\mathrm{H}_{2} \mathrm{SO}_{4}$ decomposition, the best connection option is with a VHTR (very high temperature reactor). Fig. 4 shows a connection scheme as an example, between HYTHEC and the European Project RAPHAEL. This scheme represents a self-sustainable plant concept, in which, in addition to the heat supply to the S-I cycle, the electrical demand of the internal consumers is provided by the nuclear reactor. Then, the high temperature flow coming out of the reactor is derived to an Intermediate Heat eXchanger (IHX). This IHX provides heat to a secondary loop that interacts with the S-I cycle components, improving heat recovery. The flow goes partially to the IS cycle and another part goes to a Brayton cycle for an electricity production that equals the S-I cycle consumption.

A preliminary sizing and economic feasibility of the plant has been performed. The proposed $\mathrm{H}_{2} \mathrm{SO}_{4}$ and $\mathrm{HI}_{x}$ section flowsheets have been taken as reference. VHTR data reported in Table 1 have been assumed. With these assumptions only one

Table 1

VHTR data

\begin{tabular}{ll}
\hline Nuclear power reactor $(\mathrm{MW})$ & 600 \\
$\mathrm{H}_{2}$ production & $100 \%$ \\
IHX inlet/outlet helium temperature $\left({ }^{\circ} \mathrm{C}\right)$ & $350 / 890$ \\
IHX inlet/outlet $\mathrm{S}-\mathrm{I}$ temperature $\left({ }^{\circ} \mathrm{C}\right)$ & $890 / 442$ \\
Helium mass flow rate $(\mathrm{kg} / \mathrm{s})$ & 218.93 \\
Helium pressure $(\mathrm{MPa})$ & 5 \\
\hline
\end{tabular}
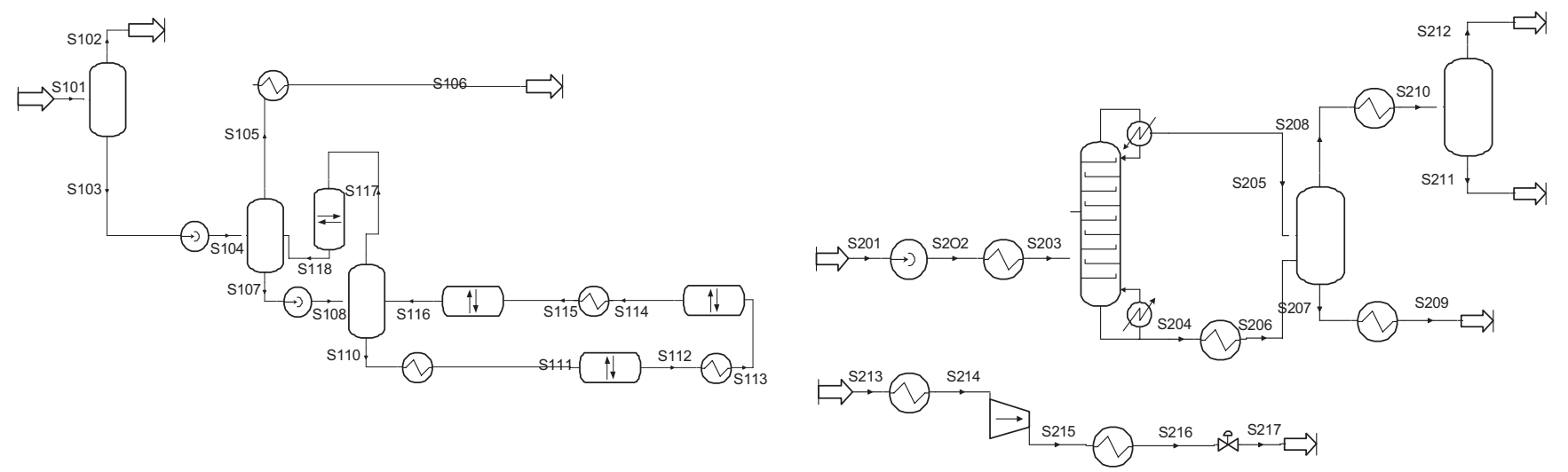

Fig. 3. S-I flow-sheet.

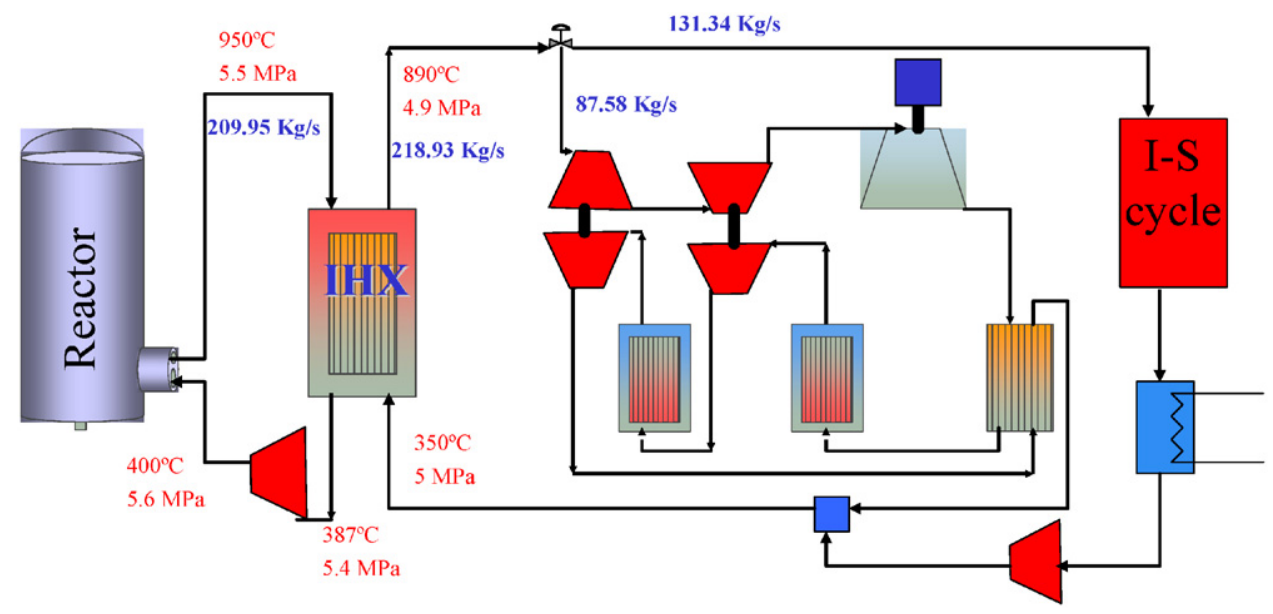

Fig. 4. S-I cycle coupling to a nuclear reactor. 


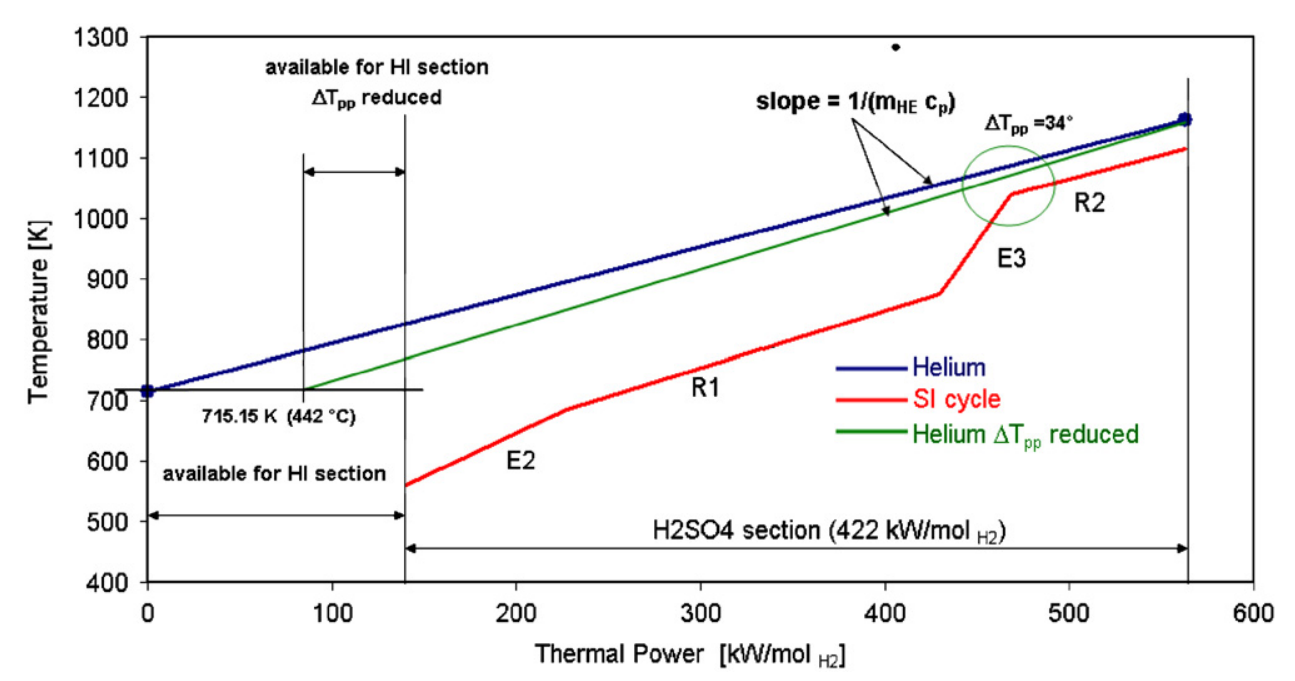

Fig. 5. Helium- $\mathrm{H}_{2} \mathrm{SO}_{4}$ section temperatures vs. thermal power (per $\mathrm{H}_{2} \mathrm{~mol} / \mathrm{s}$ ).

design degree of freedom (DOF) has to be specified to completely define the VHTR-S-I cycle matching. The temperature difference $\Delta T_{\mathrm{pp}}$ between helium and reactants at $\mathrm{SO}_{3}$ decomposition reactor has been assumed as DOF. Fig. 5 shows $\mathrm{H}_{2} \mathrm{SO}_{4}$ section temperatures profile vs. thermal power, referring to one $\mathrm{H}_{2} \mathrm{~mol} / \mathrm{s}$ production (i.e. $422 \mathrm{~kW} / \mathrm{mol} \mathrm{H}_{2}$ required by $\mathrm{H}_{2} \mathrm{SO}_{4}$ section), vs. the helium line slope. By lowering $\Delta T_{\mathrm{pp}}$ the helium mass flow needed to produce one $\mathrm{H}_{2} \mathrm{~mol} / \mathrm{s}$ decreases. Thus, for a given helium mass flow the assumption of reduced values of $\Delta T_{\mathrm{pp}}$ leads to an increased hydrogen production (i.e. increased efficiency). Concomitantly, $\mathrm{H}_{2} \mathrm{SO}_{4}$ heat transfer surfaces (and costs) increase. Moreover, for a given SI cycle helium outlet temperature $\left(442^{\circ} \mathrm{C}\right)$ a decreasing thermal power is available to feed the HI section (Fig. 5); the temperature approaches for sizing heat recovery devices are reduced and, as a consequence, heat transfer surfaces noticeably increase. After preliminary evaluations, a $\Delta T_{\mathrm{pp}}$ equal to $34^{\circ}$ seems to be a good compromise between hydrogen production (some $633.2 \mathrm{~mol} / \mathrm{s}$, with an efficiency around 30\%) and plant component sizes. Finally components have been sized and costed by using standard chemical engineering methods. Technical proposals have been given for the most challenging equipment: the $\mathrm{SO}_{3}$ catalytic decomposition reactor and the $\mathrm{HI}_{x}$ section components, which require large heat exchange surfaces and process vessel volumes because of the relevant internal heat recovery and flow rates. Suitable acid resistant materials have been selected. The cost of the $\mathrm{HI}_{x}$ section is approximately eight times greater than that of the $\mathrm{H}_{2} \mathrm{SO}_{4}$ section, and roughly $80 \%$ of $\mathrm{HI}_{x}$ section overall cost is constituted by heat recovery devices. Thus, noticeable plant cost savings are achievable by assuming higher temperature approaches. The best balance between cycle efficiency and plant cost must be obtained.

The $\mathrm{HI}_{x}$ section is the most important section for the efficiency of the S-I cycle. To design and optimise the reactive distillation column we have chosen, knowledge of the total and partial pressures of the liquid vapour $\mathrm{HI}_{x}$ mixtures is required up to $320^{\circ} \mathrm{C}$ and 100 bar. We have developed a progressive

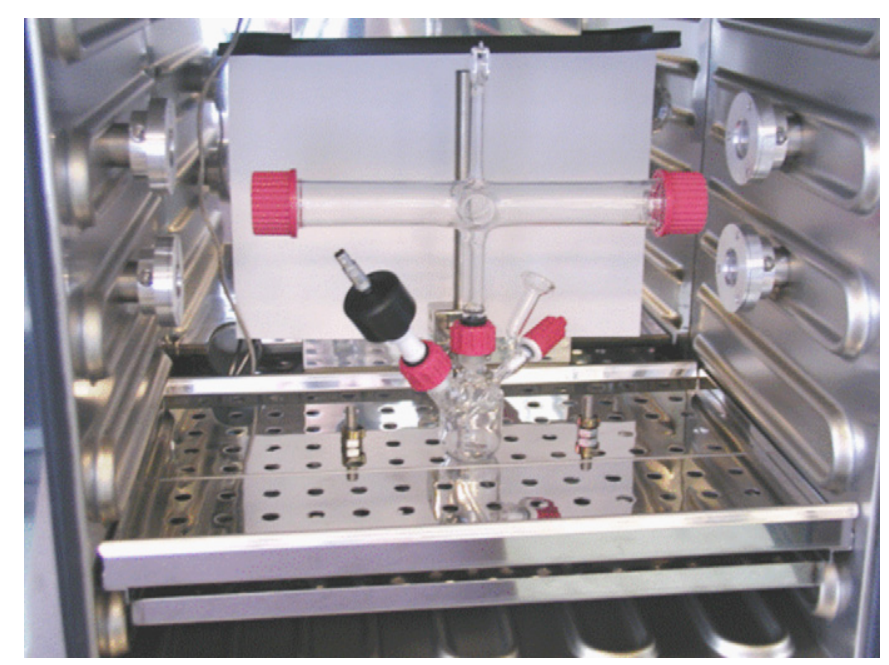

Fig. 6. Experimental I2 device.

methodology around three experimental devices which contain these corrosive and concentrated mixtures:

- I1 is an experimental device devoted to the measurement of the total pressure up to $130 \mathrm{bar}$ and $315^{\circ} \mathrm{C}$. It is composed of a microautoclave made of tantalum and placed in a thermoregulated oven. A pressure gauge equipped with a tantalum membrane enables the pressure measurements for different $\mathrm{HI}_{x}$ compositions. First experiments have been completed with water up to $30 \mathrm{bar}$ and $240^{\circ} \mathrm{C}$. The solution introduction procedure has been validated.

- I2 is an experimental device devoted to the qualification of the analytical diagnostics for partial pressure measurements up to $130^{\circ} \mathrm{C}$ and 2 bar (Fig. 6). It is composed of a glass cell equipped with a total pressure gauge and placed in a thermoregulated oven. This cell is equipped with two optical pathlengths because optical "online" diagnostics have been chosen for partial pressures measurements in order not to 


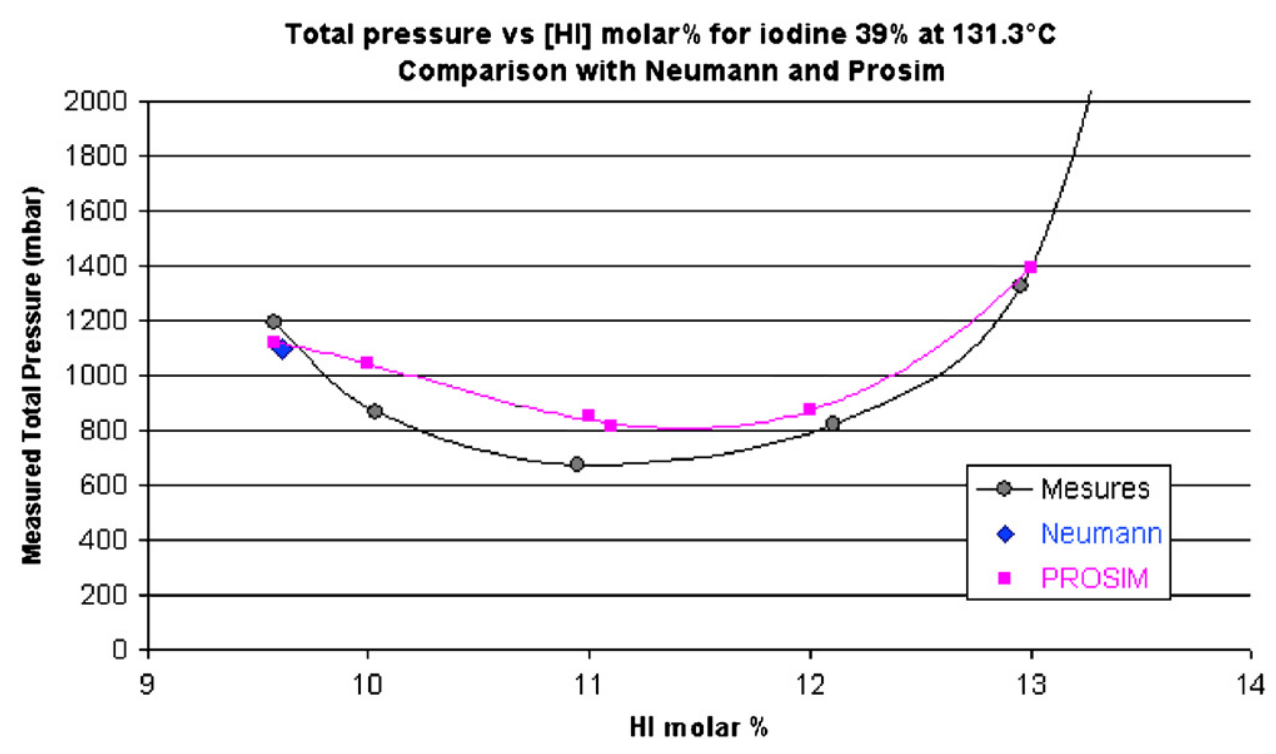

Fig. 7. I1 device/total pressures for ternary systems.

alter the vapour composition and prevent tedious manipulations. UV-visible spectrometry has been chosen to measure iodine concentration and FTIR spectrometry for $\mathrm{HI}$ and $\mathrm{H}_{2} \mathrm{O}$ concentration measurements.

- I3 is an experimental device under construction devoted to the partial pressure measurements of the $\mathrm{HI}_{x}$ mixtures in the process domain. It is composed of the I1 device equipped with a vapour chamber. The same "online optical techniques" are used. Raman spectroscopy is also under evaluation.

Total and partial pressure measurements have been conducted in the experimental device I2. Pure samples, binary $\mathrm{HI}-\mathrm{H}_{2} \mathrm{O}$ and ternary $\mathrm{HI}-\mathrm{H}_{2} \mathrm{O}-\mathrm{I}_{2}$ mixtures have been studied; the results have been compared with the literature and with Prophy code. Up to the azeotrope, a good agreement is observed, beyond the azeotrope, the total pressure measured is higher than the pressure calculated. Ternary systems with an iodine composition close to the Bunsen exit ( $39 \%$ molar) have also been studied and exhibit the same behaviour beyond the azeotrope (Fig. 7). A design of experiments exploring different iodine compositions is currently under way. The objective of the work is to collect unknown data, especially beyond the azeotrope, which will be included in Prophy code for the scaling of HI reactive distillation column.

\subsection{The use of membranes to improve the $S-I$ cycle $H I_{x}$ section efficiency}

Applying a liquid phase membrane separation unit to the $\mathrm{HI}_{x}$ processing section has two potential advantages, an increase in efficiency and less extreme operating conditions. A membrane separation process could be used to separate the $\mathrm{H}_{2} \mathrm{O}$ and $\mathrm{HI}$, thus having the effect of dehydrating the $\mathrm{HI}_{x}$ by removing some water from the process stream. The membrane separation unit is considered in the following system positions: on the column feed, at the column reboiler and on a column sidestream.

Ideally the membrane would allow HI through and reject water and iodine as there is much less HI than water and iodine in the feed stream. In the majority of membranes, however, it is likely that $\mathrm{H}_{2} \mathrm{O}$ will have a higher flux than $\mathrm{HI}$. The amount of water removed from the $\mathrm{HI}_{x}$ stream depends on the fraction of the feed that is distilled and the flux ratio of the components. A distillation column can separate the distillate to give the azeotrope and pure water [5]. As iodine is present there may be added complications due to membrane fouling and a high HI vapour pressure.

The three key factors that need to be considered when selecting the membrane unit are

- The solution is a highly corrosive, strongly acidic, aqueous system.

- The process temperature is $398 \mathrm{~K}$.

- The membrane must be selective to either $\mathrm{HI}$ or $\mathrm{H}_{2} \mathrm{O}$.

Both PTFE and ceramic membranes fulfil these criteria [5]. Recent work in America shows that Nafion-117 membranes can be used in a pervapouration process to remove water from aqueous HI [6]. The results are very promising for the application of liquid phase membrane separations to the SI process.

In order to investigate the effect of dewatering, simulations were carried out using the process flow-sheeting code ProSimPlus, using a modified version of the process flow-sheet which includes the membrane separation unit. The membrane is modelled as a splitter with zero enthalpy drop. This means that the retentate exits at a lower temperature than it would in practice. This is accounted for in the heat integration and so will not significantly affect the efficiencies calculated.

The base efficiency of using a 50 bar column with no membrane separation unit is 0.379 . As shown in Fig. 8, with $9 \%$ 


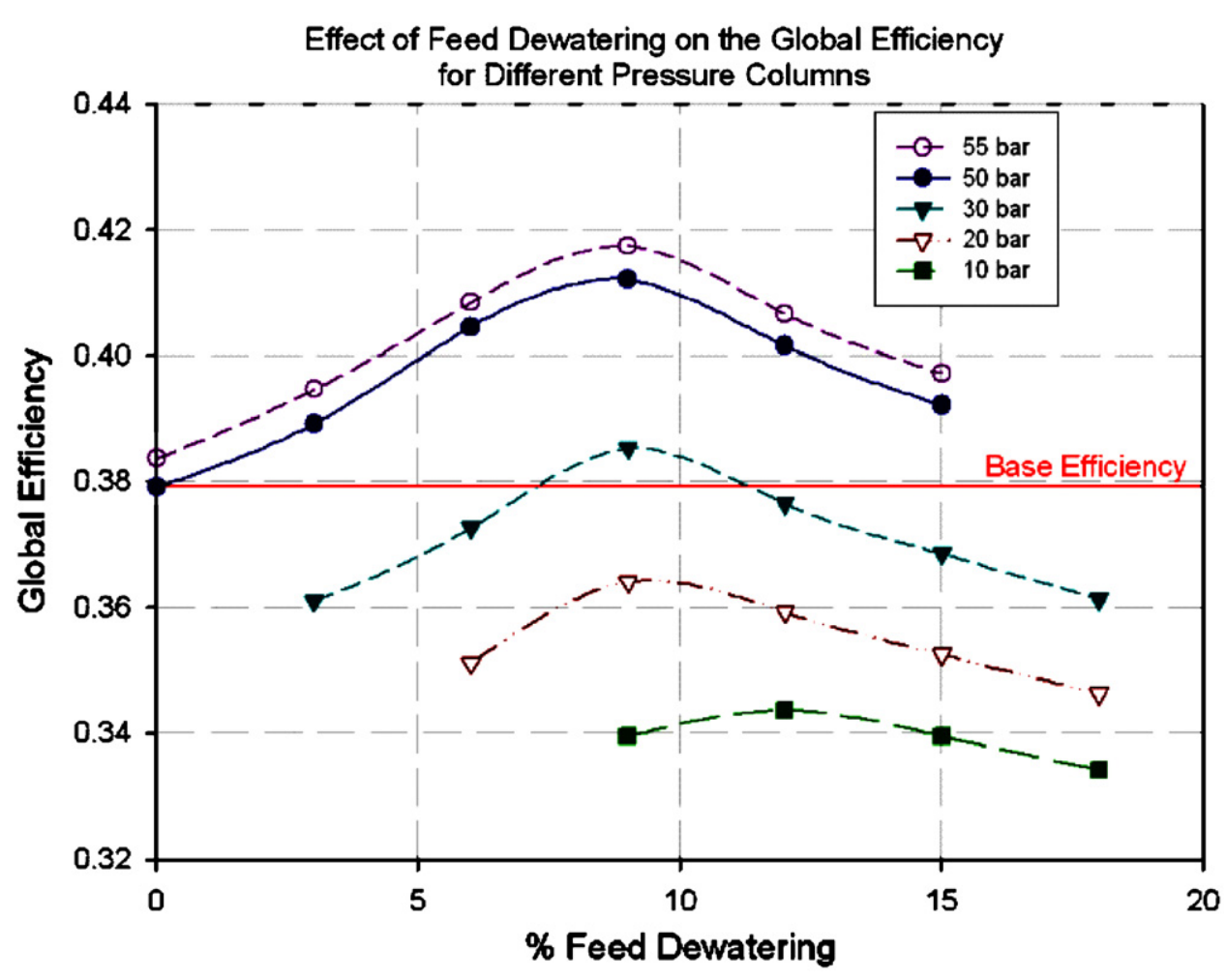

Fig. 8. The effect of feed dewatering.

feed dewatering this value is increased to 0.412 , a significant increase. A maximum in efficiency occurs as the power required by the pump and that required surplus to heat integration decrease, whereas the additional power required by the heat pump increases. Using a 55 bar column the maximum efficiency obtained is 0.418 , again at $9 \%$ feed dewatering. As the column pressure decreases the efficiencies obtainable also decrease. With approximately $7 \%$ feed dewatering a 30 bar column has the same efficiency as the 50 bar column with no membrane. A decision as to the best column pressure would depend on a detailed sizing and cost evaluation. With $1 \% \mathrm{HI}$ removal along with $9 \%$ dewatering the maximum efficiency decreases to 0.401 , as seen in Fig. 9. Although this is lower than with no $\mathrm{HI}$ removal it is still considerably better than the efficiency obtained with no membrane unit.

Placing a membrane separation unit at the column reboiler or on a idestream increases the efficiency slightly although it never exceeds 0.382 . The simulations therefore suggest there is little benefit in applying a membrane unit in this way.

\subsection{Assessment of the WH thermo-chemical cycle, for a solar and/or nuclear driven process}

The co-application of electrolysis and the thermo-chemical step in the WH process offers the opportunity for a combined use of heat and power. The required thermal and electrical energy can be either provided by a nuclear reactor or by concentrated sunlight. This opens a wide variety of operational strategies. Hybrid solutions including solar and nuclear energy input are conceivable and are analysed with regards to their technical and economic feasibility. Different operation and plant concepts are generated, including the solar and nuclear supply of heat for the thermo-chemical step and of nuclear and solar power for the electrolysis step. For this purpose, the possible coupling schemes are modelled to enable optimisation of the cycle energy balances and efficiencies. The plant concepts are analysed with regards to their economic potential, particularly in comparison with the S-I process. The overall flow-sheet of the WH process is given in Fig. 10.

\subsection{Development of a dedicated solar receiver-reactor for the decomposition of sulphuric acid}

The decomposition of sulphuric acid $\left(\mathrm{H}_{2} \mathrm{SO}_{4}\right)$ is a highly heat consuming, and at the same time technically challenging, step in the S-I cycle as well as in the WH cycle. One important task in the framework of this project is the investigation of sulphuric acid decomposition by concentrated sunlight in the DLR solar furnace in Cologne. The focus of the investigation is the development of a technology and a process to allow the coupling of concentrated solar radiation into the $\mathrm{H}_{2} \mathrm{SO}_{4}$ splitting process.

One of the major findings of a former project was a significant enhancement of the splitting of $\mathrm{SO}_{3}$ when using concentrated solar radiation as the energy source for that reaction. This was due to a photolytic effect of concentrated solar radiation on the $\mathrm{SO}_{3}$ molecules [7]. Under solar irradiation and temperatures above $1100 \mathrm{~K}$ there is an irradiance-dependent photochemical increase of conversion, giving the chance to operate the process without a catalyst or to accelerate the reaction and 


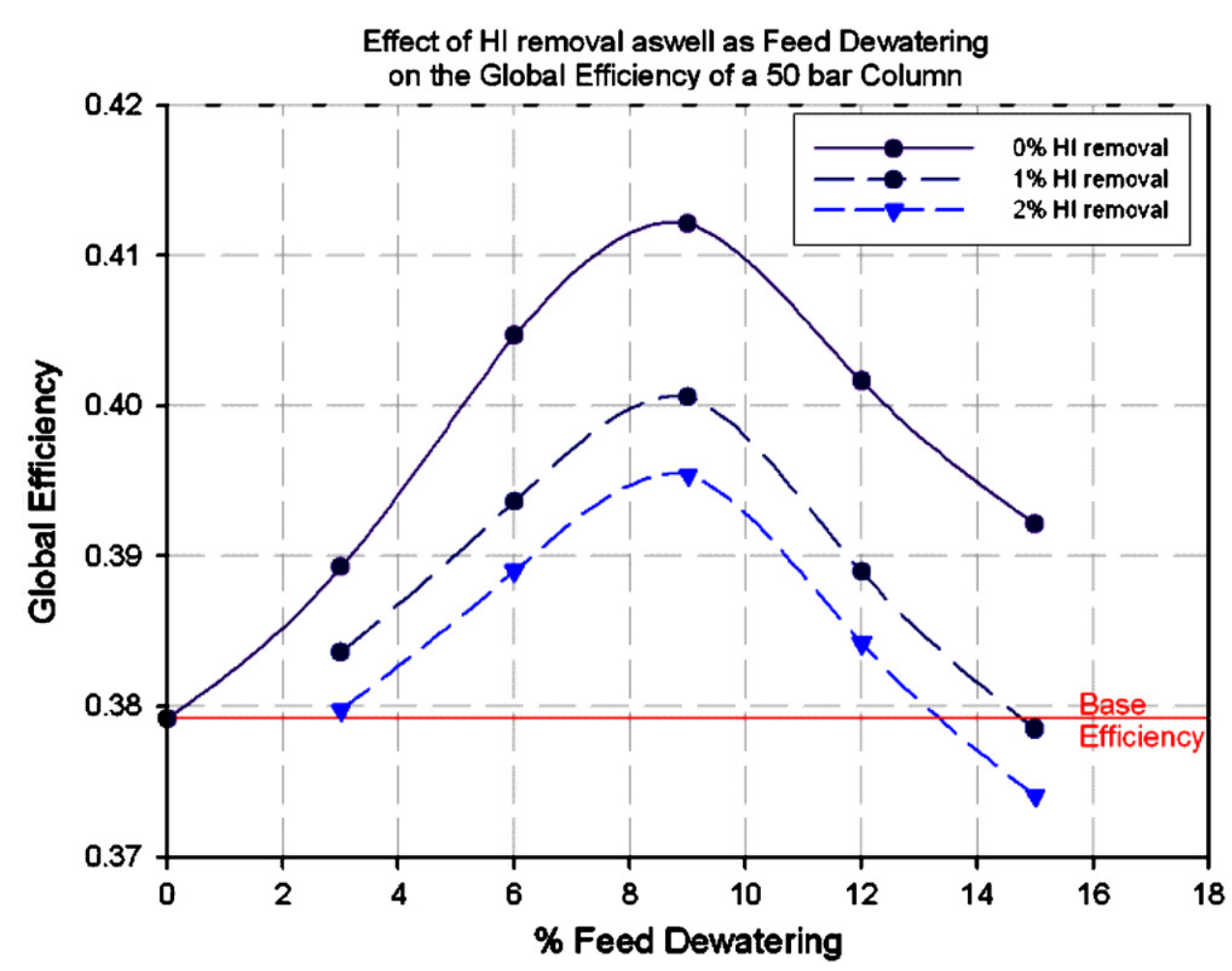

Fig. 9. The effect of feed dewatering with HI removal.

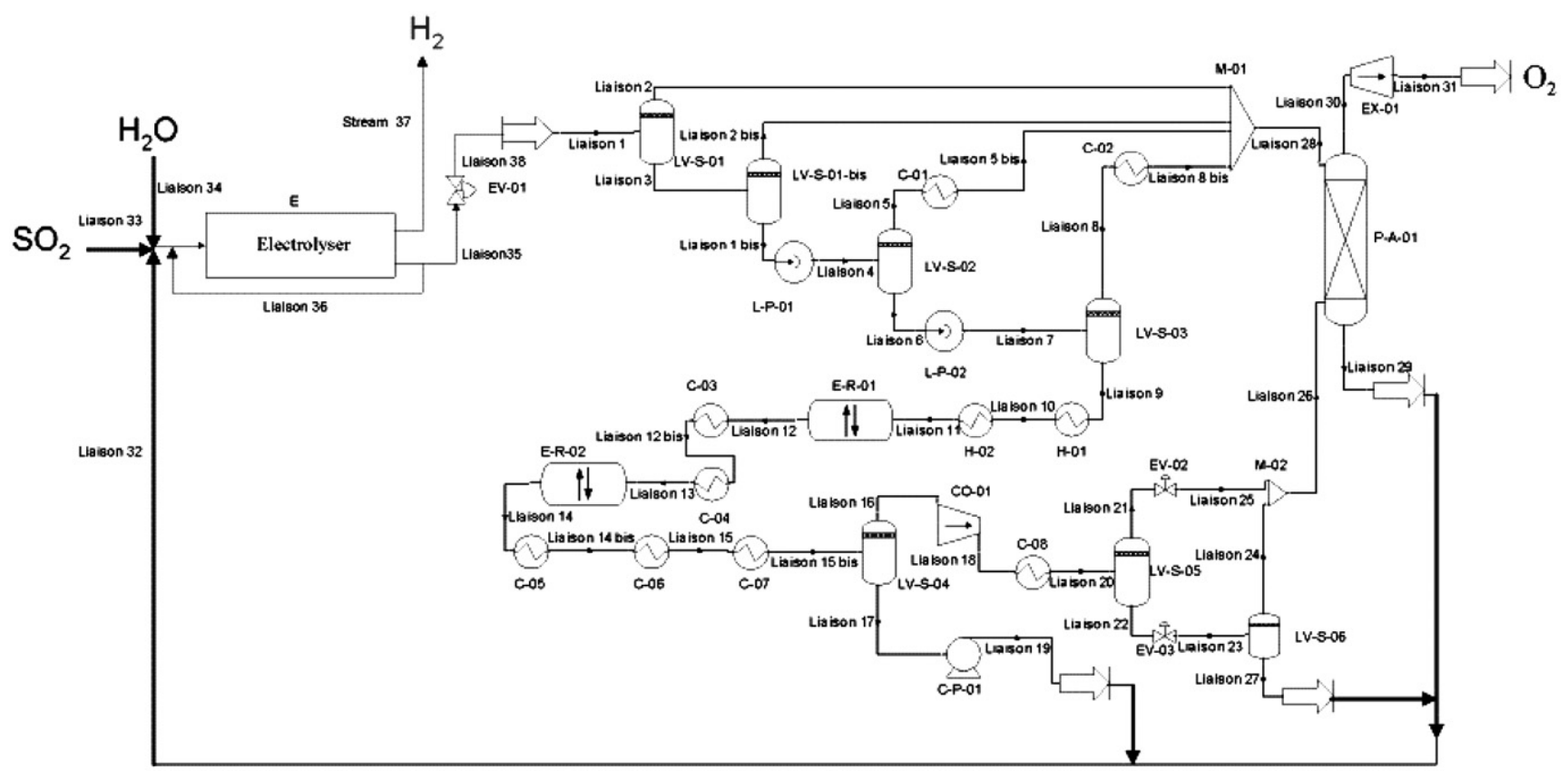

Fig. 10. Overall flow-sheet of the Westinghouse process.

thereby to increase the potential throughput. This effect is only advantageous if a receiver-reactor is used which allows for direct absorption of sunlight by the reactants itself.

According to this, the goals of the current activity are the development of a direct absorbing receiver-reactor and of a corresponding process, the verification of their feasibility and viability with respect to the splitting of sulphuric acid, and their assessment in comparison to other reactor and process concepts.

The primary goal of the activity described was the development of the necessary hardware for the solar process, which includes as a key component a dedicated converter capable of directly absorbing concentrated solar radiation, which is the 
so-called receiver-reactor. The radiation is typically absorbed by volumetric absorbers or even by the reactants themselves and thus enables reaction temperatures up to $1300^{\circ} \mathrm{C}$. Therefore, the employment of a catalyst is only optional. Direct absorption also enables a potential photo-assisted acceleration of thermal decomposition and compactness of plant design by avoiding additional heat exchangers.

Due to these characteristics offering the potential of achieving higher efficiencies it was decided to investigate and put into practice a concept of a direct absorbing receiver-reactor, which was called the porous absorber reactor.

\subsection{Porous absorber receiver-reactor}

The appliance of porous structures for an evaporation process and the subsequent decomposition reaction was derived from the volumetric receivers which are typically applied for the heating of heat transfer media in solar power plants [8] or for chemical reactions like the reforming of methane in dedicated receiver-reactors [9]. In power plants solar radiation is concentrated on the front face of a porous absorber. A heat transfer medium, mostly air, passes through this absorber to be heated. The heat is transported to the inner part of the absorber by convection and conduction. By that the heat exchanging area is enlarged to the whole volume of the absorber, which constitutes the so-called volumetric effect. In the case of the reforming reaction the solar heat absorbed by the absorber is used to power the reaction of methane with water to form synthesis gas. Therefore, the reactants pass through the heated porous structure.

Those concepts had to be adapted to the requirements of the two-step splitting reaction of concentrated $\mathrm{H}_{2} \mathrm{SO}_{4}$. These requirements are connected to the characteristics of corrosive liquid and gases, to the performance of a change of phase, to the kinetics of the reactions involved, and to the required temperature levels. The central innovation of the concept is the execution of an evapouration process, the evaporationof sulphuric acid, in a solar heated porous structure. Therefore, the related reactor was called the porous absorber receiverreactor. The idea is to feed the liquid sulphuric acid onto or to directly inject it into a solar heated porous structure to initiate a rapid and homogenous evapouration of the acid at the inner surface of the porous structure. The necessary heat is supplied by the sun and transferred to the liquid by the porous structure. During and directly after the evaporation the sulphuric acid is dissociated. The resulting $\mathrm{SO}_{3}$ molecules have to be split into $\mathrm{SO}_{2}$ and $\mathrm{O}_{2}$ to provide the necessary feed for the ensuing step of the S-I cycle and WH cycle, respectively. For the execution of this splitting step another porous structure is foreseen.

Due to the different temperature levels and requirements needed for the evaporation and dissociation of the acid $\left(350-550^{\circ} \mathrm{C}\right)$ on the one hand, and for the spitting of $\mathrm{SO}_{3}$ without catalyst $\left(1000-1200^{\circ} \mathrm{C}\right)$ on the other hand, two porous components had to be implemented to meet the requirements of each reaction step individually. For the evaporation step a foam with a large inner surface was chosen. The splitting step shall be carried out in a honeycomb structure stable and robust enough to stand the required temperature level and capable of being coated by catalyst materials if necessary.

The choices of size of the two components and their spatial arrangement have already been adapted to the characteristics of the concentrated radiation as provided by the solar furnace in Cologne. Those characteristics are in particular the rotational symmetry of the beam, the smallest diameter of this beam in the focal plane of about $130 \mathrm{~mm}$, and the consideration of different flux densities in different axial positions along the optical axis. This means that the component with the higher required temperature level, the honeycomb, has to be located nearer to the focal plane than the foam evaporator.

Due to the temperature level and due to the corrosive potential of the reactants only $\mathrm{SiSiC}$ seems feasible for the honeycomb structure. Different options are conceivable as construction material for the foam vapouriser with $\mathrm{SiSiC}$ as the favourite option.

A detailed final design has been prepared and accompanied by the following methodical steps:

\subsubsection{Elaboration of design principle}

The main design principle is the employment of a modular arrangement of ceramic components for the reaction containment to ensure a maximum of flexibility regarding replacement of individual elements and to ensure a sufficient compensation of thermal and mechanical stress. This modular way of construction necessitates the integration of high temperature resistant seals between elements. This is realised by applying ceramic fibre seals and high temperature resistant mastic. A modular reactor concept enables a variety of possibility to change, enhance, and optimise the set-up. The design of the receiverreactor comprises as main elements the ceramic components $(\mathrm{SiSiC})$ as heart of the reactor which contains the reactive zone; a window; a housing; a support for the central ceramic part of the reactor; a flange junction between reactor and off-gas line; a suitable inlet enabling the feed of liquid sulphuric acid into the reactor. Fig. 11 shows the design principle of a porous absorber reactor to fulfil those requirements.

\subsubsection{CFD and FEM analysis of the draft design}

Both reactor concepts, aerosol and porous absorber reactor, have been investigated and compared with a finite element model using ANSYS as well as with computational fluid dynamics (CFD) to assist in enhancing and optimising the geometry and arrangement of components. The modular assembly and multi-step processing promise a better thermal and structural behaviour of the reactor compared to the aerosol reactor design. Simulations and parametric analyses proved this hypothesis to be correct (Fig. 12). The effect of the size (diameter) and position (distance from the honeycomb structure) of the foam vapouriser, the effect of the position of the focal plane in the axial direction of the reactor and the effect of the solar flux power have been studied. The temperatures of components are within the thermal-use range, the reactor thermal behaviour assures sufficient temperature distribution and heat transfer. Structural 
deformations and stresses are acceptable, the quartz window holder design is appropriate and no leak tightness hazards are foreseen. Fluid behaviour is expected to approach theoretical conditions for an efficient reaction performance.

Also the modelling of the thermo-fluid dynamic aspects has shown a satisfactory behaviour of the porous absorber reactor. The simulations predict that the use of porous structures turns out a good solution to achieve a uniform temperature field in the

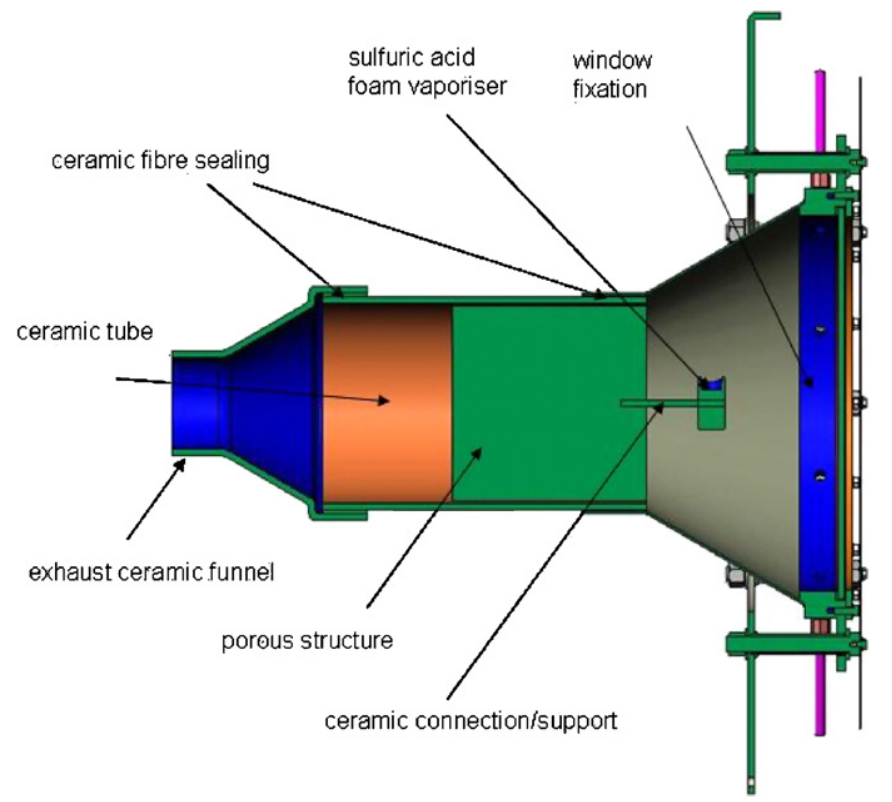

Fig. 11. Draft design of porous absorber reactor. reactor body (Fig. 13). Moreover they seem suitable to allow a homogeneous vapourisation and an adequate residence time in order to achieve a sufficient dissociation rate.

\subsubsection{Thermographic inspection of foam vapourisers heated by convection}

Cylindrical ceramic foams were heated by hot heat supplied by a blower-heater. After achieving a certain temperature level the foam was fed with water droplets. The droplets impinged on the foam at a depression at the topside of the foam and penetrated into the foam. The number of droplets per second was varied by a dispenser. Three different regimes of operation were observed by thermographic inspection of the foam.

In regime A a comparably high temperature of the foam is combined with a comparably low flow of liquid. This leads to an excess of the so-called Leidenfrost temperature of the liquid. This means that straight after a brief contact with the foam a thin film of vapour is built surrounding the individual droplets. The film decreases the heat transfer to the droplet significantly and thereby delays the vapourisation process. As a consequence, the droplets cross the surface with little friction and exit the foam without being vapourised.

If the foam is charged with higher volume flows of liquid at constant heat supply the regime changes (regime B). Due to the higher heat demand for the evapouration, the temperature significantly decreases in a zone adjacent to the impingement of the droplets $\left(<200^{\circ} \mathrm{C}\right)$. The surface temperature falls below the Leidenfrost temperature of the liquid. The foam is wetted and the liquid is completely vapourised without any liquid exiting the foam (Fig. 14).

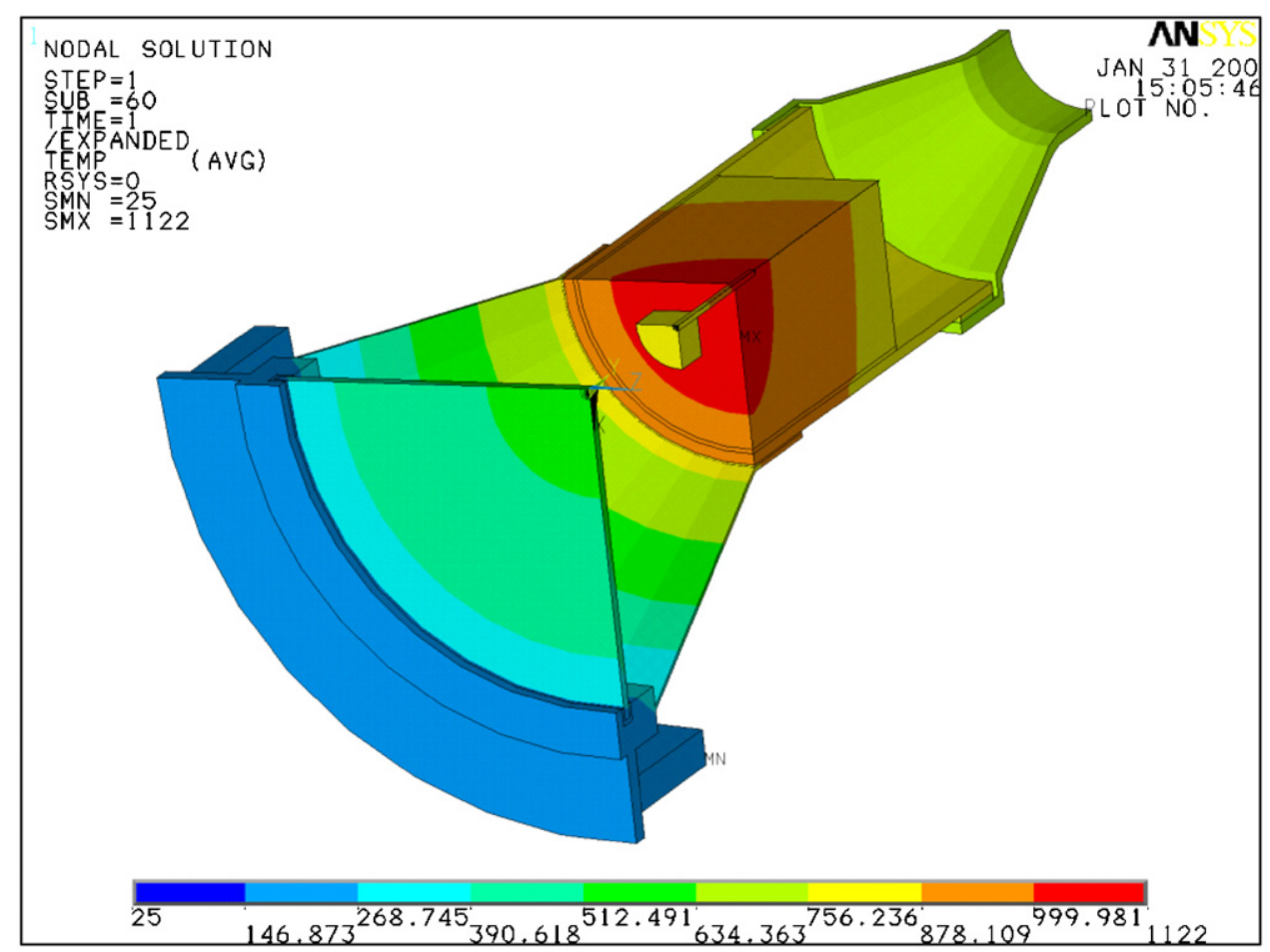

Fig. 12. FEM simulation- $\frac{1}{4}$-expansion thermal results. 


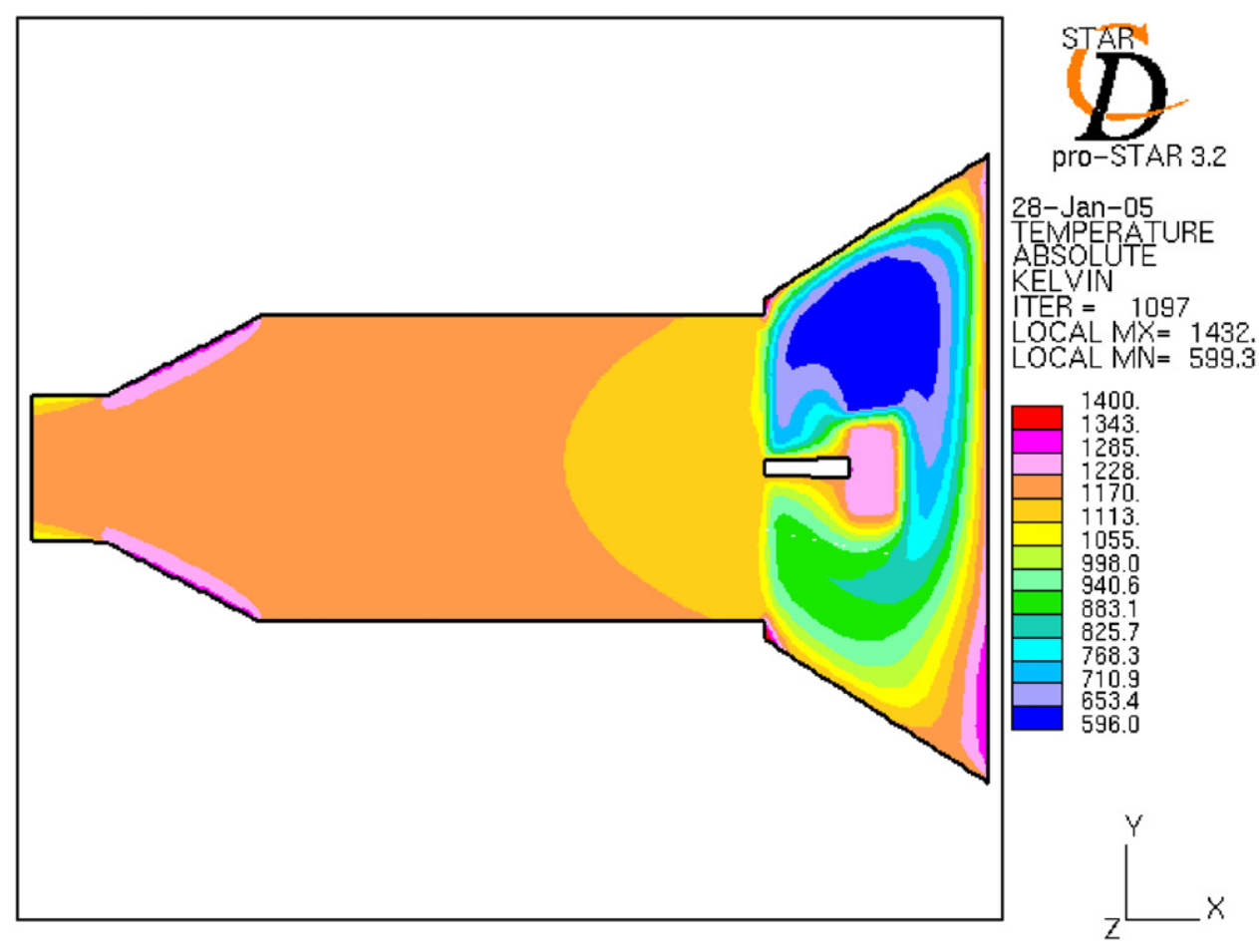

Fig. 13. 2-D simulation of the fluid temperature distribution in the porous absorber reactor.
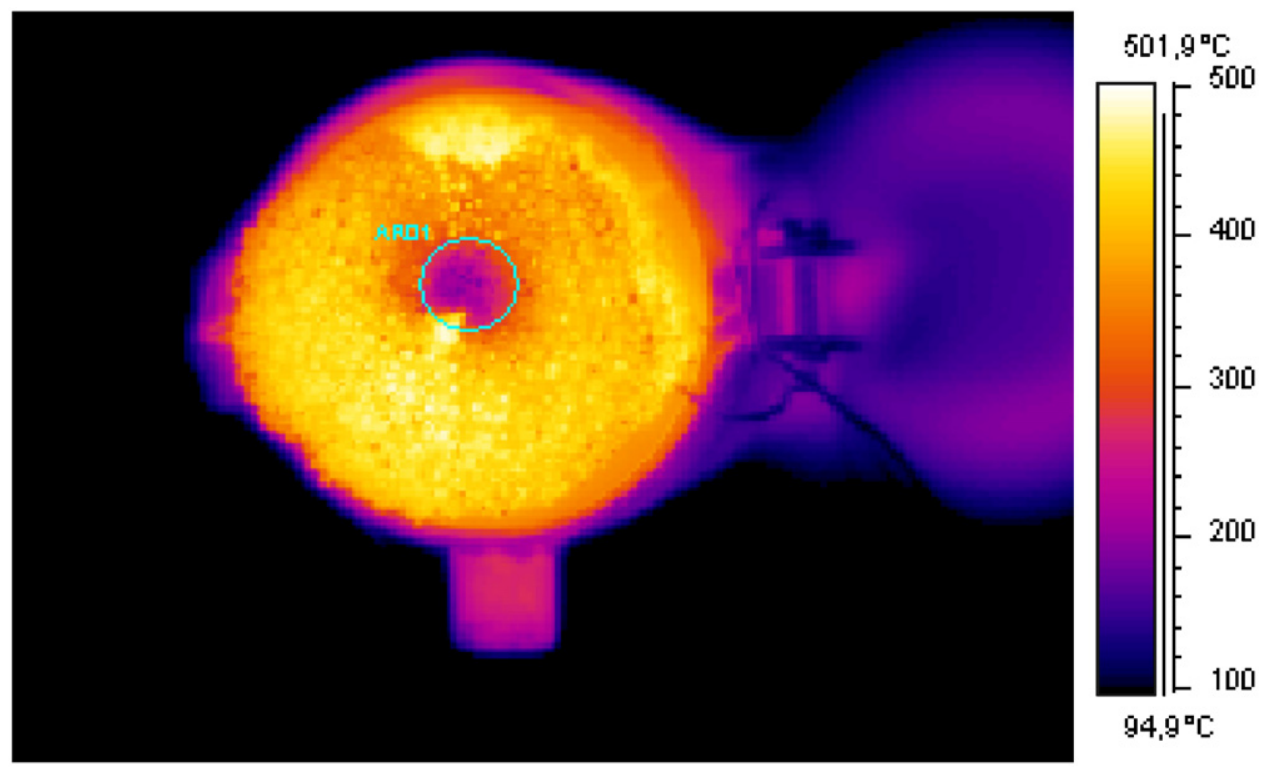

Fig. 14. Thermo-graphical picture of the foam in regime B.

Application of even higher volume flows of liquid combined with lower maximum temperatures lead to another regime of operation (regime $\mathrm{C}$ ) which is not desirable. The foam is more than completely wetted and the heat supply is too low to vapourise the complete amount of liquid. Therefore a part of the liquid passes and exits the foam without being vapourised.

\subsubsection{Kinetics of $\mathrm{H}_{2} \mathrm{SO}_{4}$ decomposition}

The decomposition rate of $\mathrm{H}_{2} \mathrm{SO}_{4}$ in a laboratory-scale reactor heated by means of an electric furnace was measured for sev- eral experimental temperatures and initial sulphuric acid concentrations. A significant kinetic barrier to the decomposition of $\mathrm{H}_{2} \mathrm{SO}_{4}$ was observed even for large residence times (> $40 \mathrm{~s}$ ) in the high temperature reactor. Satisfactory reaction yields $(>90 \%)$ were obtained only at temperatures higher by about 300-350 K compared to thermodynamic predictions (Fig. 15).

\subsubsection{Preliminary solar experiments}

The focus of a preliminary experimental campaign carried out with a model reactor of another project was the test of performance of the foam vapouriser's capability to vapourise 


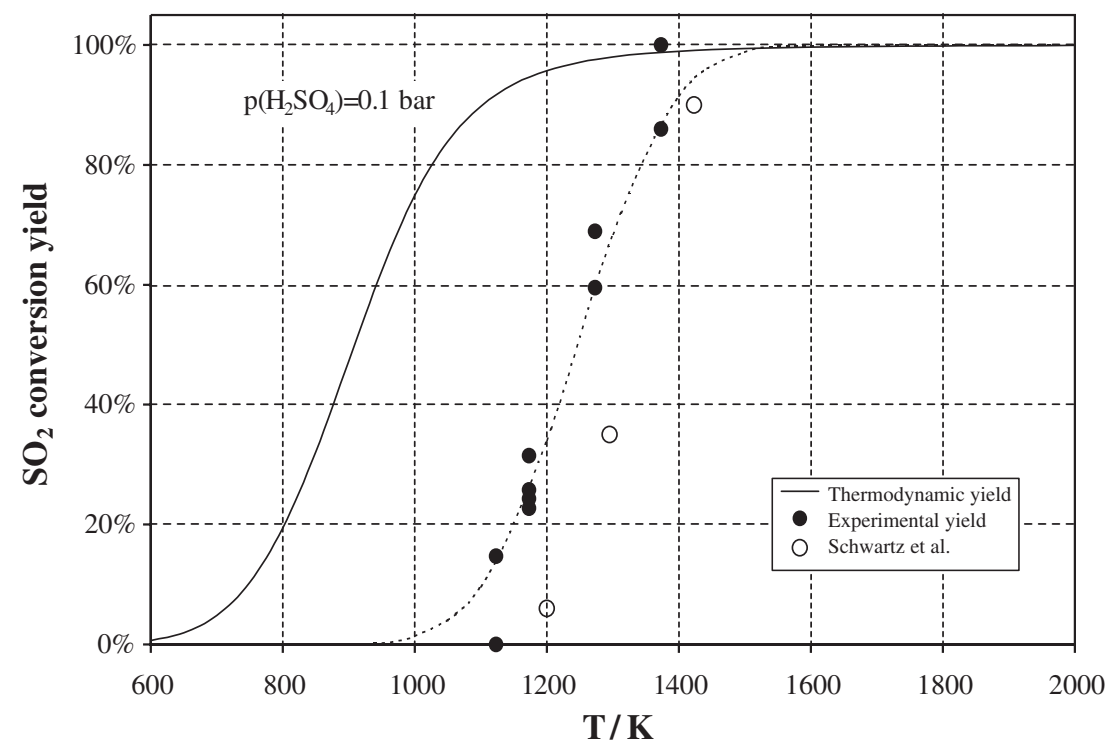

Fig. 15. Experimental and computed reaction yield for the $\mathrm{H}_{2} \mathrm{SO}_{4}$ decomposition at high temperature.

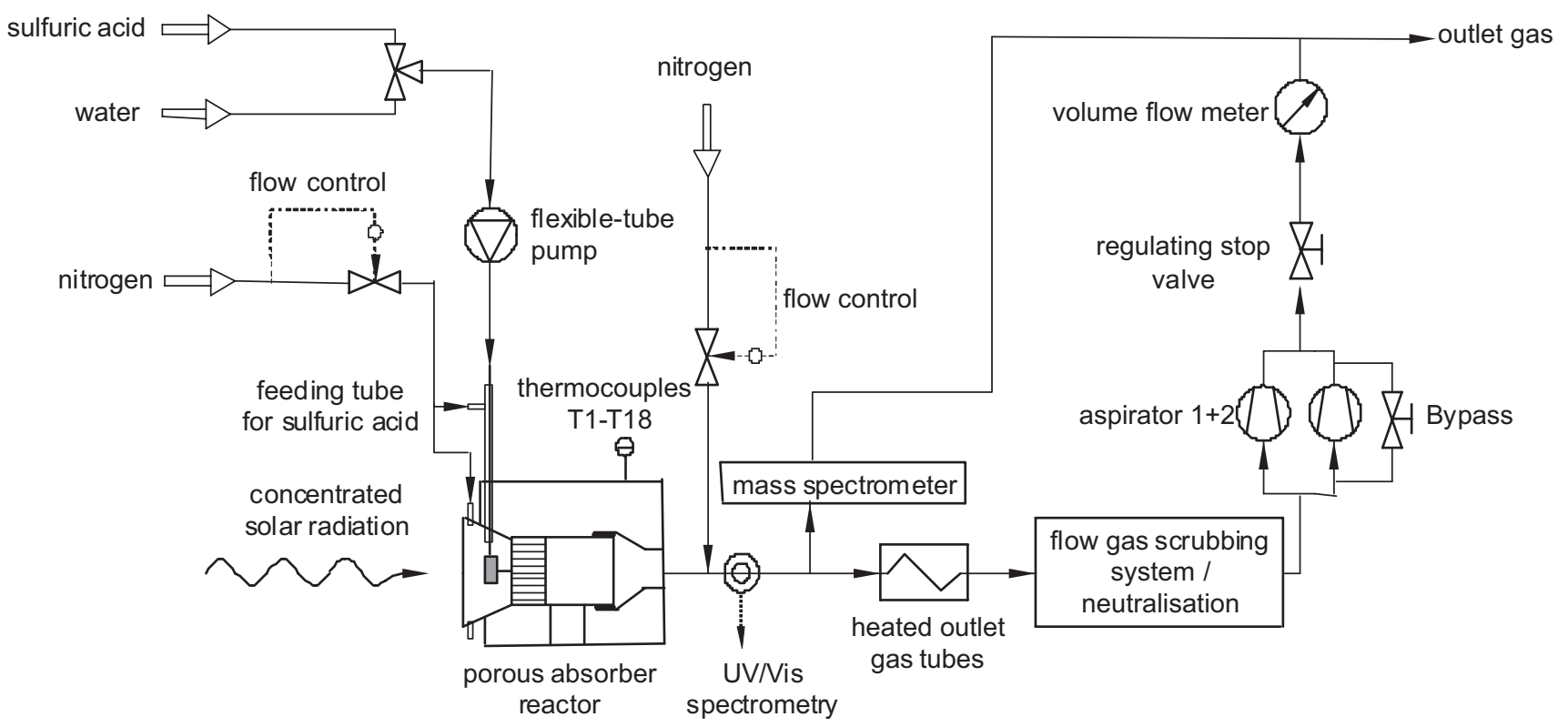

Fig. 16. Functional scheme of test facility for solar decomposition of sulphuric acid in the solar furnace.

liquids at a porous structure heated by a solar furnace, and the investigation of temperature levels and distributions available in such reactors. The test series was carried out with water instead of sulphuric acid as the layout of the model reactor did not exhibit the necessary corrosion resistance. The principle of the set-up is depicted in Fig. 16. It has been modified for the HYTHEC experimental campaign by integrating the foam evapourator and a suitable inlet for the liquid. The mass flow of feed water is continuously adjusted in a manner that ensures operation in the above-mentioned regime B without a Leidenfrost effect and without passage of liquid water at the bottom side of the foam.
The shadowing of the honeycomb by the foam vapouriser is a rather minor effect if the diameter of the foam is restricted to about $40 \mathrm{~mm}$. The evapouration of a liquid in a solar heated porous structure was shown to be feasible. The vapourisation process proceeded satisfactorily for liquid volume flow in the range $0.25-0.4 \mathrm{~g} / \mathrm{s}$ using the big foam and $0.2-0.3 \mathrm{~g} / \mathrm{s}$ using the smaller foam. In that range the process was completely controllable. The temperature level achieved within the honeycomb was shown as sufficient high for the homogeneous decomposition of $\mathrm{SO}_{3}$. The major part of its volume exhibits a temperature level beyond $1000^{\circ} \mathrm{C}$. In steady state the maximum temperature difference is lower than $225 \mathrm{~K}$. The amount of volume flow 


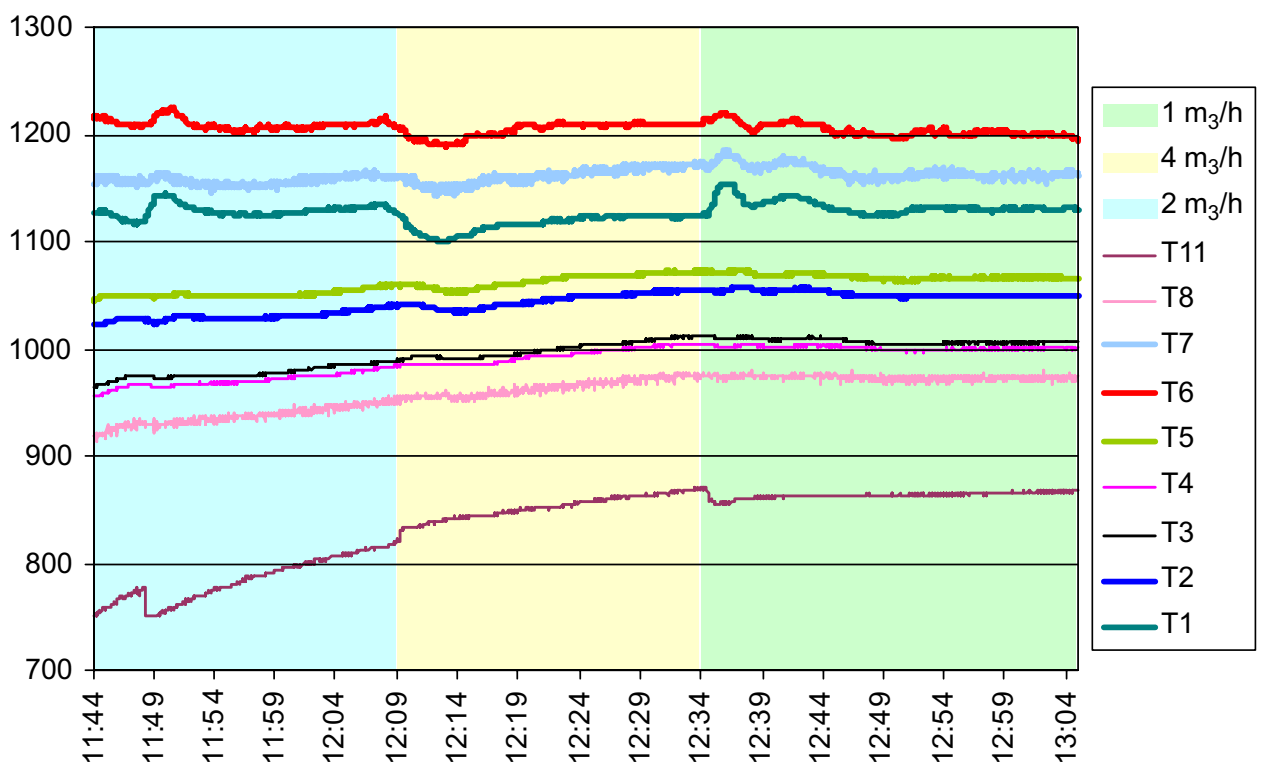

Fig. 17. Influence of volume flow of flushing gas on temperatures.

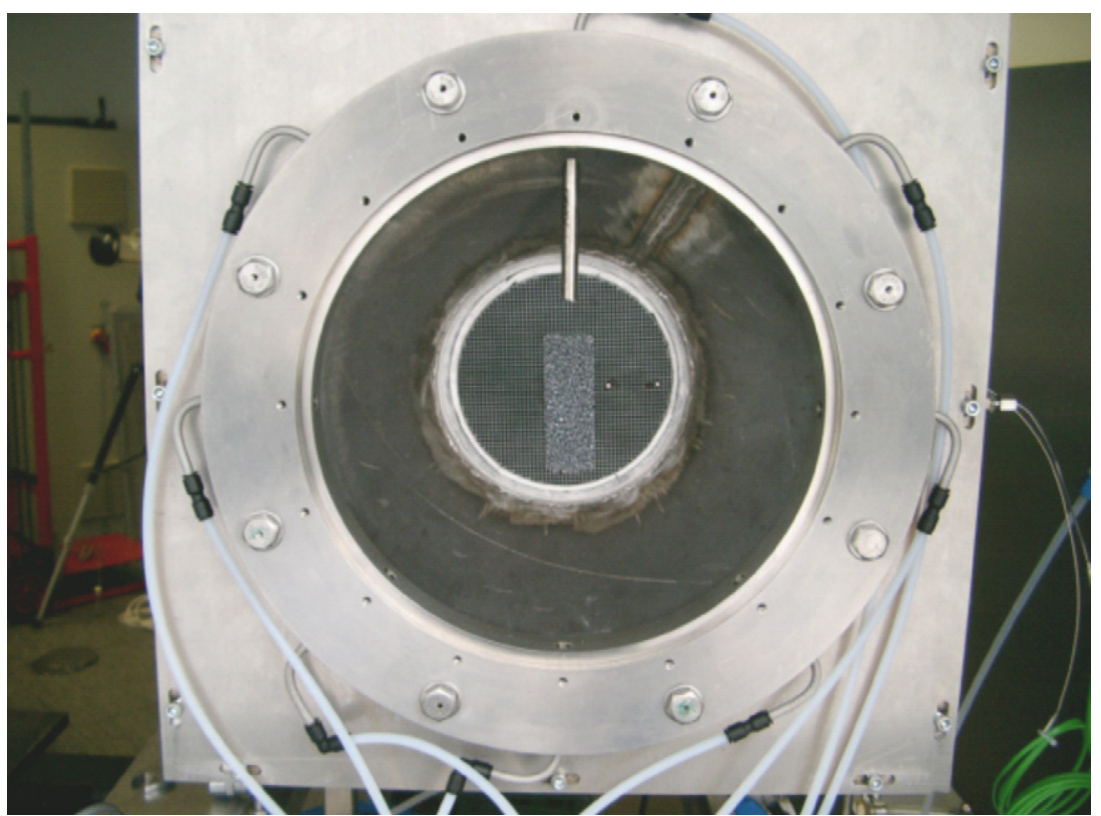

Fig. 18. Front view of porous absorber reactor after mounting.

of flushing gas has only a minor influence on the temperatures inside the honeycomb (Fig. 17). In principle it is preferable to minimise this amount to prolong the residence time of the reactants in the reaction zone and to minimise losses due to the warming of that flushing gas. At a temperature level of up to $1200^{\circ} \mathrm{C}$ in the honeycomb the necessary solar input was about $10 \mathrm{~kW}$ when operating without quartz windows. The net power was about $2.5 \mathrm{~kW}$. No significant impact of the evapourating liquid on the quartz was observed. A straightforward start-up procedure was possible by cooling the feeding tube by flushing gas and by temporarily diminishing the solar power. By that means the partial evapouration of liquid in the feeding tube could be avoided and the foam vapouriser could be operated in the suitable temperature regime (regime B see above).

\subsection{Construction and test of operability}

Based on the results of experimental pre-tests and the described reactor modelling the design of the porous absorber reactor has been refined yielding the hardware, after manufacture, as shown in Fig. 18. It has been installed and tested in the solar furnace in Cologne with the following results. 
The receiver-reactor behaved well during the first experimental campaign in the solar furnace. About $75 \mathrm{~h}$ of operation were performed. A flow of concentrated sulphuric acid was completely vapourised inside a porous absorber made of SiSiC. Other ceramic materials turned out or appear, respectively, not suitable for the solar vapourisation of sulphuric acid. Cooling of the feeding tube and an additional device (a temperature resistant "duct" for the liquid acid) ensured a vapourisation process without any splashing and impacts on the window. Sulphuric acid was homogeneously decomposed without the use of catalysts with conversions between $20 \%$ and $55 \%$. No visible corrosion occurred at the ceramic parts of the reactor. Some metallic parts of the reactor and off-gas line experienced corrosion at their surface if the temperatures at those positions were allowed to fall below the condensation point of $\mathrm{H}_{2} \mathrm{SO}_{4}$.

It can be stated that the concept of a porous absorber receiverreactor has proven feasible in a first step to decompose concentrated $\mathrm{H}_{2} \mathrm{SO}_{4}$ by solar radiation. Further steps aim now at the stepwise improvement of the conversion and of the operating procedure. The main focus of the upcoming experiments and the accompanying modelling of the reactor is the evaluation of the capability to scale-up the concept to a commercial scale and to operate the solar process with satisfactory conversion and efficiency.

\section{Conclusion}

HYTHEC is a European collaboration involving a restricted number of partners (six, in five countries) to give a first evaluation, both on technical and economic points of view, of an interesting route for future $\mathrm{H}_{2}$ production, via promising $\mathrm{CO}_{2}$ free thermo-chemical cycles: mainly the sulphur-iodine cycle, and to a lower extent the WH cycle as an alternative "hybrid" solution. Acquisition of the input data and first modelling, flow-sheeting, construction of the devices and measurement techniques, as well as industrial scale-up and techno-economic evaluations have been performed up to now. The first, S-I cycle $\mathrm{HI}_{x}$ section experimental results have been obtained.
A technology and process to allow the coupling of concentrated solar radiation into the $\mathrm{H}_{2} \mathrm{SO}_{4}$ splitting process has been developed; it can be stated that the concept of a porous absorber receiver-reactor has proven feasible for this purpose.

\section{Acknowledgement}

This project is funded by the European Community - Sixth Framework Program Priority [6.1]—Sustainable Energy Systems, Medium to Long Term (contract number: 502704).

\section{References}

[1] Besenbruch GE et al. GA-A18257, 1982

[2] Nakajima H, Ikenoya K, Onuki K. et al. Closed-cycle continuous hydrogen production test by thermochemical S-I process. Kagaku Kogaku Ronbunshu 1998;24:352 (in Japanese).

[3] Roth M, Knoche KF. Thermo-chemical water splitting through direct $\mathrm{HI}$ decomposition from $\mathrm{H}_{2} \mathrm{O}-\mathrm{HI}-\mathrm{I}_{2}$ solutions. Int $\mathrm{J}$ Hydrogen Energy 1989;14(8):545-9.

[4] Goldstein S, Borgard J-M, Vitart X. Upper bound and best estimate of the efficiency of the iodine sulphur cycle. Int J Hydrogen Energy 2005;30(6):619-26.

[5] Elder RH, Priestman GH, Ewan BC, Allen RWK. The separation of $\mathrm{HI}_{x}$ in the sulphur-iodine thermochemical cycle for sustainable hydrogen production. Trans IChemE, Part B, Process Safety Environ Prot 2005;83:343-50.

[6] Orme CJ, Jones MG, Stewart FF. Pervapouration of water from aqueous HI using Nafion-117 membranes for the sulfur-iodine thermochemical water splitting process. J Membrane Sci 2005;252:245-52.

[7] Lüpfert E, Funken K-H. In: Becker M, Böhmer M, editors, Solar thermal concentrating technologies. Proceedings of the eighth international symposium, vol. 3, Köln, Germany, October 6-11, 1996, Heidelberg: C.F. Müller-Verlag, 1996.

[8] Fend T, Hoffschmidt B, Pitz-Paal R, Reutter O, Rietbrock P. Porous materials as open volumetric receivers: experimental determination of thermophysical and heat transfer properties. Proceedings of the 11th SolarPACES international symposium on solar power and chemical energy technologies, 2002. p. 379-387.

[9] Tamme R, Buck R, Möller S. Advanced hydrogen production with concentrated solar power systems. Proceedings of ISEC 2003 international solar energy conference, Hawaii, USA; 15-18 March 2003, ISEC200344085. 